\title{
Migrant mental health and representation in routine administrative registers
}

\section{Close, Ciara Mary}

2018-02

Close , C M , Bosqui , T , O'Reilly , D , Donnelly , M \& Kouvonen , A M 2018 , ' Migrant mental health and representation in routine administrative registers ' , International Journal of Migration, Health and Social Care , vol. 14 , no. 1 , pp. 82-95 . https://doi.org/10.1108/IJMHSC-09-2016-0035

http://hdl.handle.net/10138/234146

https://doi.org/10.1108/IJMHSC-09-2016-0035

acceptedVersion

Downloaded from Helda, University of Helsinki institutional repository.

This is an electronic reprint of the original article.

This reprint may differ from the original in pagination and typographic detail.

Please cite the original version. 


\section{Migrant mental health and representation in routine administrative registers}

\section{Abstract}

Purpose: There has been an increase in the use of registers and record linkages to study migrant mental health. However, the accuracy of these registers and the degree to which they are representative of the migrant population in Northern Ireland (NI) are unclear. This study explored: (i) the coverage of the NI migrant population in GP data and Census records, (ii) the issues faced by migrants in terms of registering and accessing the local health system; and (iii) the reporting of racial hate crimes against migrants to police.

Design: Two focus groups of professionals $(n=17)$ who worked with migrants were conducted. Group discussions were guided by a research-informed topic guide and the data were analysed using thematic analysis.

Findings: Three main themes emerged: (i) Issues with the use of GP registration, Census and hate crime data for researching migrant mental health (ii) Barriers to health service use (eg low cultural awareness among health staff and access to interpreters) and (iii) Risk factor exposure and mental health status in migrant communities (e.g. poverty, isolation and poor working conditions).

Originality/ value: Record linkage and registry studies of migrant health and well-being using Census and health service sources need to be mindful of the likelihood that some migrants may be missed. The possible underrepresentation of migrants in health registers may be explained by reduced use of such services which may be caused my encountering staff with limited cultural competency and the inability to access an interpreter promptly. 


\section{Migrant mental health and representation in routine administrative registers}

\section{Introduction}

Migration to many European countries has increased substantially in recent years (Dustmann and Frattini, 2011). For example migration to Northern Ireland (NI) more than doubled between 2001 and 2011 (Krausova and Vargos Silva 2014). Such population changes mean that there is an immediate need to improve our understanding about the health of migrants in order to aid research-informed decision making in policy development and service improvement. Migrant health has previously been studied in several Scandinavian countries using register based linkage studies (Hollander 2013, Norredam 2014) and in an attempt to replicate this type of research in a NI context researchers at the Administrative Data Research Centre Northern Ireland (ADRC-NI) at Queen's University Belfast (QUB) are planning to conduct a large-scale linkage study into the health of migrants, initially focusing on mental health. The proposed registers for linkage are the Census, General Practitioner medical doctor (GP) and the Police Service of Northern Ireland (PSNI) hate crime data registers. These registers allow individual prescription medication, for example antidepressants, to be linked to individual socio-demographic and economic data from the Census, as well as to neighbourhood data such as area deprivation from the Census, and neighbourhood hate crime levels from the PSNI. This linkage study could therefore provide high quality data on the incidence of mental health disorders amongst migrant groups in NI, and may also set an example to other European Union (EU) countries wishing to gather an updated evidence base on migrant mental health. 
The quality of these register-based studies is thought to be high due to the often whole population coverage, making generalization of findings reliable. These samples are highly representative, have low levels of missing data, and reduce the likelihood of research biases because they are drawn from real life data. Many of these studies have been conducted in Nordic countries where data linkage methodologies are well-established, and these datasets are known to have a high level of quality and accuracy (Patel et al., 2017). Less is known about countries with less-established systems. The risk of compromised data from low quality data - due to poor record keeping, inconsistencies in prescription coding and dispensation (such as cross-border agreements) and differences in the accessibility and availability of health services, Census information, and Police for migrant groups - is higher.

The Administrative Data Research Centre in NI (ADRC-NI) is a relatively recent development, along with Centres across the UK, that specifically focuses on using whole population register-based datasets. This Centre brings together researchers from Queen's University Belfast (QUB), the University of Ulster (UU) and the government body Northern Ireland Statistics and Research Agency (NISRA), to conduct research in the public interest using primarily GP and Census registers, among others. We are interested in determining the strengths and caveats of the Census and GP registers for accurately quantifying migrants and their need for, and use of, mental health services, to inform future research on migrant populations and their mental health needs. Determining the accuracy of these methods for quantifying migrants is important as it will help shape policy and resource allocation.

Despite the fact that many countries such as the UK, France and Spain rely primarily on the Census for quantifying their migrant population, the method may underestimate migrant populations. Research from the United States has shown that non-English speaking individuals are less likely to complete the Census than English speakers and this is likely the case in the UK (US Census Bureau 2012). In NI the use of GP register data may be a more 
accurate method of quantifying the migrant population given the current need for residents of $\mathrm{NI}$ to be registered with a GP in order to access primary and secondary care services. However, it is important to bear in mind that there is wide variation in health care systems around the world and only some countries (e.g. within the UK) health care system includes a GP as the central point for accessing primary and secondary care services, including mental health services. Research suggests that some migrant groups living in the UK, such as asylum seekers and refugees, experience difficulties registering with a GP and may be less likely to be registered with a GP (Refugee Council 2013). Limited English language skills and poor access to appropriate interpreters has been suggested as one such barrier for migrants trying to register with a GP (HealthWatch 2015) as well as discrimination and prejudice at the point of access (Phillimore, 2011).

Aside from quantifying migrants in Census and health registers, using these registers to assess mental health, and mental health service needs, faces further challenges. Limited cultural competency of health professionals has been highlighted as a major barrier to migrants accessing mental health services. Some migrant groups may also be particularly suspicious of mental health services and some may have had previous negative experiences of services; all of which are likely to negatively impact migrants' access of mental health services (Franks et al. 2007, Keynejed, 2008). Furthermore, mental illness is described differently in different cultures and terms frequently used to describe mental ill-health in English e.g.: "feeling down" or "blue," when translated directly to another language may yield meaningless expressions (Matsumoto, 2010). Without basic knowledge on how mental illhealth is described and perceived in specific cultures health professionals may fail to identify migrants suffering mental illness and migrants may be deterred from accessing professional support for mental illness.

In addition to quantifying migrants and their mental health and mental health service needs, the ADRC-NI studies plan to explore the effect of common risk factors on migrant mental 
health, including socio-economic disadvantage using the Census and exposure to hate crime using PSNI crime registers. Migration has been linked to increased risk of mental ill-health in many countries (Lindert et al. 2009, Bronstein and Montgomery 2011, Borque et al. 2011), and one of the largest contributory factors, alongside socio-economic disadvantage, has been found to be exposure to racism and discrimination (Veling et al. 2007, Be`cares et al. 2009). Quantitative data on the occurrence of racial hate crime in $\mathrm{NI}$, held on the PSNI regional hate crime register, suggests that racial hate crime has increased in recent years (Police Service of Northern Ireland, 2014). However, it is unclear how accurate these figures are, and it is possible that a proportion of hate crime goes unreported. A report "Voices for change" (NICEM, 2014a) which included some qualitative research with Black and Minority Ethnic (BME) groups, suggested that racism was a growing issue in $\mathrm{NI}$, but was often not reported to authorities. The report highlighted that this under reporting was due to beliefs that reports would not be believed or that reporting would make no difference. Further qualitative exploration of racial hate crime reporting in NI may be helpful as it will allow a greater understanding of the level of underreporting, which could better inform the proposed registerbased linkage study by NI researchers on migrant mental ill-health and its risk factors.

Migrant support organisations employ professionals in roles such as interpreters, nurses, volunteers and community development workers who provide support to migrants. These professionals, many of whom are migrants themselves, may be able to offer important insights into migrant health and well-being and issues related to using routine administrative registers for conducting migrant health research. Discussions with such professionals could help improve our understanding on migrant health issues e.g.: experiences of the health system, filling out the Census or reporting a hate crime. These are the kinds of issues that professionals working with migrants are faced with every day. 


\section{Aim}

To elicit views about (i) the coverage of the NI migrant population in GP and Census records,

(ii) the issues faced by migrants in terms of accessing and using the local health system; and (iii) the reporting to police of racial hate crimes against migrants.

\section{Methodology}

The reporting of this study was guided by the consolidated criteria for reporting qualitative research, COREQ (Tong et al. 2007). This 32-item checklist for interviews and focus groups, allows for the clear and complete reporting of qualitative studies

\section{Study design}

This study used focus groups to elicit professionals' views on the topics under investigation. The purpose of this focus group study was to inform a linkage study on the quantification of migrants in registers and the mental health and mental health service need of migrant groups, which plans to utilise GP, Census and hate crime registers to determine if migrants are at risk of mental health inequalities and to determine the strengths and caveats of these registers for capturing migrants' use of and need for mental health services.

Focus groups undertook a simple qualitative descriptive approach. This approach is recommended when a direct description of a specific phenomenon is required and such methods are particularly helpful for researchers wishing to find out the, who, where, what of experiences and events (Sandelowski, 2000).

\section{Ethical approval}


This focus group study was given ethical approval by the School of Medicine, Dentistry and Biomedical Sciences Ethics Committee at Queen's University Belfast (Reference number 14/54v2).

The associated linkage study was given ethical approval from the Office for Research Ethics Committee Northern Ireland (ORECNI) (Reference Number 15/WM/0212).

\section{Inclusion/ Exclusion criteria}

Potential participants invited to take part in focus groups were adults (aged 18 years or older, male and female); and were professionals working with migrants in a supportive role (paid/voluntary) or a manager of an organisation that supports migrants.

\section{Recruitment}

Professionals were invited to participate via the research teams' existing collaborative connections with migrant and health organisations in Northern Ireland including the Northern Ireland Council for Ethnic Minorities (NICEM) and The Public Health Agency (PHA) in NI. Managers and migrant support workers in these settings disseminated a participant information sheet to relevant professionals. Professionals interested in participating then contacted the researcher directly or contacted the Migrant Support Worker/ Manager who provided them with the study information. At this point, participants were given an opportunity to ask further questions. At recruitment the participants were made aware that the researcher conducting the focus groups had a specialised interest in migrant mental health and the focus group findings would be used to inform a related register-based linkage study. 


\section{Data collection}

Participants provided written consent on the day of the focus group indicating that they were willing to participate voluntarily in the focus groups and they agreed to the discussions being recorded. Focus groups were conducted in 2015 , one was conducted in a migrant support organisation and the other was conducted in a health organisation. Only the participants and moderator were present at both focus groups.

Focus groups were recorded with the use of an electronic audio digital recorder and were moderated by a female researcher, Ciara Close $(\mathrm{CC}, \mathrm{PhD}) . \mathrm{CC}$ has received training in qualitative research as well as conducting various qualitative studies including focus groups for previous research projects. CC had not met any of the study participants prior to the focus groups commencing.

A pre-determined topic schedule used to guide focus groups (appendix 1). The researcher took notes during focus groups and these were later added to the transcripts.

Focus groups are normally ongoing until data saturation has been reached, which is often after three focus groups. Unfortunately, due to the time restrictions of this project, this meant that that the number of focus groups had to be restricted to two.

\section{Data analysis and rigour}

Focus group findings were analysed using the Newell and Burnard (2006) framework for thematic analysis. Two researchers (CC and TB) analysed the findings using this framework independent of one another and then came together to agree codes, categories and themes. 
Ensuring the rigor of qualitative research is very important if qualitative research is to be considered credible and as such several of the strategies recommended by Creswell and Miller (2000) for improving the rigor of qualitative studies were used in the current study. This included member checking, completing a detailed audit trail and peer debriefing.

\section{Results}

Focus group participants

The purposive sample of participants that took part in the focus group study included 17 professionals, 2 others had agreed to participate but failed to attend, one of whom contacted the researcher and informed her she was sick. The two focus groups lasted 60 and 75 minutes respectively and generated lively discussions. A summary of the transcripts were sent via email and confirmed by each study participant.

The participants were both female (15) and male (2). Most participants worked in paid employment (15) and just two worked in volunteer roles. All participants were either working directly to support migrants or were leading an organisation that supports migrants and had been on average 5.4 years in their current role. Ten professionals attended focus group one, and seven attended focus group two. The mean age of participants was 48.3 years (age range 19-66 years) and several were migrants themselves (6/17) (Table 1). Specific details of each focus group participant's job roles are detailed in Table 2, which highlights the wide range of participant experience and expertise on the challenges facing migrants living in NI.

Analysis and Themes 
The data was coded by two researchers independent of one another; this was done manually without the use of specific software. Three major themes and nine sub-themes became clear on examining and coding the focus group data (Table 3).

\section{Major theme 1: Issues with the use of GP registration, Census and hate crime data for} researching migrant health. When focus group participants were asked questions around the representativeness and accuracy of GP, Census and hate crime registers, a key theme that emerged was "Issues with the use of GP registration, Census and hate crime data for researching migrant health," under this major theme, four sub-themes became apparent:

Sub-theme 1.1: Migrants experience difficulties completing the Census and do not recognise its importance. Some focus group participants indicated that some migrants have issues completing the Census and these included language barriers and issues in accessing an interpreter:

"The language barrier ....phone [call for Census completion] is in English and you never know will people do it [access an interpreter]...it's another step for them [non-English speaking migrants]," PN1

"I think I do have a comment on this. For the past two Census' they have used interpreters and my problem is that these centres in the community - they don't help people. As [sic] although the Census did a super job there are some people that did ring for an interpreter and it didn't happen," PN 2

Some participants indicated that the importance of the Census, and the need to complete it, is not recognised by some migrants: 
"Some people don't have the status to stay here so they don't see it as important to fill in the Census," PN 15

"Sometimes when a person comes here as a migrant worker and in their heart they don't plan to stay long, but the reality might be different, but when you asking them for their data they will say 'but I haven't been here that long'," PN12

Sub theme 1.2: Migrants' experienced issues with registering with a GP. It became clear that some groups of migrants encountered difficulties registering with a GP. For EU migrants this centred on being asked to produce paperwork to register with a GP that EU migrants are not required to possess in order to reside in $\mathrm{NI}$ :

"Mostly Portuguese working in factories in the Dungannon area.... Some of them had tried to register for the local practices but for different reasons were not able to. For example for some of them it was because they didn't have a passport because they travelled on an ID card so that was a problem," PN4

"Sometimes it's an awareness issue when they go to reception. Sometimes they are asked for ID or sometimes they would ask for a visa or a document. But for me as a Polish person I don't have a document with a visa as I don't need it ....but they could say because you don't have a document with a visa then you can't register ...so it is really down to lack of awareness ... and if someone had an issue with a visa this would put them off registering,"

\section{PN 14}


There was also an apparent lack of awareness about the local health system in NI, with some migrants unaware they had to register with a GP and others unclear about what to do and where to go when a GP surgery is unable to take on new patients:

"At the beginning when they are applying for asylum...even just the knowledge and awareness of how to register with the GP [is lacking], and it really depends on what GPs [sic] and some GPs have no space... who [sic] have too many and can't take on anyone new,"

\section{PN1}

"They don't know where to go, that is a barrier [to GP registration]," PN9

"The other barrier is not realising that they have to do it [GP registration]," PN16

There was also sense that many migrants do not see the importance of registering with a GP and some go elsewhere if they have a health problem:

"Yes in India you don't have your GP only if you were sick would you go to the GP and then you could go to a consultant to see an ENT consultant [or] whatever it is that is wrong with you, so you don't have to wait for you GP to refer ...so if they come healthy they may not see the need to register," PN12

"I would say that some migrant workers may be late to register with the GP - they are young and healthy they come to work and then there is no urgency there to register and they will just go to pharmacy and get some medicine,"PN15 
Sub theme 1.3 Underrepresentation of some migrant groups in routine administrative registers. There was a sense that some migrants may not appear in registers that collect routine data of the population because they do not have legal access to services:

“But some of them [undocumented migrants] don't want to come out ...because if they use health services then you may become known to immigration ....and that's why people may be just washing dishes for hours to keep them in money, "PN1

"It very difficult to pinpoint the undocumented ones but I would say it's mainly in the fishing and hospitality industries you would find that those are [sic] but generally people don't speak about that ... but definitely it's the fishing and hospitality that I feel they are mostly in," PN4

"There will be a lot of Philippine people who come over to work on the boat and are not able to access any services except $A$ \& E," PN5

1.4 Challenges in reporting hate crime. There was a general consensus that that hate crime was frequently underreported to authorities, for various reasons. Some migrants felt disheartened by the lack of prosecution of perpetrators of hate crime and this was a commonly cited factor in underreporting:

"The PSNI [Police Service Northern Ireland] set up a bilingual advocacy service, from which we are part of, you know one of the tasks is to encourage the reporting of hate crime so people are there trying to encourage people to report, but the reporting is one thing, but then if they don't get prosecuted then, or prosecuted for a lesser offence than the hate crime, or the charges have been dropped, then that discourages people [to report] again," PN12

"They [a migrant family] have been getting these comments for years but the police said unless there is something written on the wall or the property is damaged there is nothing we 
can do about it. It's been to court and Victim Support have been sending them letters to say I am sorry about what is happening to you, and they went and got their own solicitor and everything, and she was absolutely devastated when she was here the other night, it's just that feeling of complete powerlessness and not knowing what to do and who to turn to, they have been given this advice and exhausted all avenues that they [can] think [of], [then] for the same thing to happen two nights later," PN 7

Other focus group participants reported that they believed that in NI there was a higher tolerance for verbal abuse and this may play a role in underreporting:

"But then again when you look at it in comparison with the indigenous population - from my nursing [experience] those who have got a good kicking or a head injury being in the wrong place, that was already tolerated [before migration increased] and in existence between the two sides [Catholic and Protestant communities] so that wasn't very healthy to begin [with],"

\section{PN5}

"I was at a conference 18 months ago and some of their remarks by people from other countries and other ethnic backgrounds is that when they first came here, that in NI we had a very high tolerance for verbal abuse and people slinging insults at one another, and I suppose that's a legacy of the Troubles [civil conflict in NI] for want of a better word, so there is this polarisation already in society...somehow they have normalised a level of conflict that would be unacceptable in most other societies,"PN3

Other narratives suggested that for some migrants underreporting may be related to fear of drawing attention to themselves, and that initial reporting of racial hate crime tends to be to community leaders as opposed to formal authorities: 
"It's [underreporting] also is related to the fear of drawing attention to themselves," PN16

"Sometimes they [migrants] may feel more comfortable going to someone in the community that has their language [to report hate crime]," PN12

Major theme 2: Barriers to local health service use. Participants discussed at length migrants' experiences of the $\mathrm{NI}$ health system, and these discussions were focused on areas in need of improvement:

Subtheme 2.1: Lack of cultural awareness among health staff. Large differences between GPs in Great Britain and NI in the quality of health staff knowledge about health issues more prominent in migrant communities, particularly Female Genital Mutilation (FGM), were identified:

"An example of one of the women who would be more vocal where she was in with the Doctor - and they had to call another Doctor in as they had never seen anything like this [FGM] before whereas in the [rest of the] UK it is completely different [better]," PN7

Some participants identified that the lack of cultural awareness of health staff may be related to limited cultural competence training in $\mathrm{NI}$ :

"It's the perception that we don't have that problem here [FGM] it is a learning curve and [health] Trusts need to have some training on FGM to make staff aware of this issue," PN1 
“They [social workers] don't know a lot about the issues these people [migrants] face...part of it is about competence, we are not training social workers up on this [cultural awareness]," PN2

Sub theme 2.2. Issues accessing interpreters. For some migrants they may have to wait long periods of time for health service appointments due to difficulties in accessing interpreters in a timely fashion:

"But what I am saying is that for some languages it is taking up to a week to get an interpreter in the appropriate language, 'PN6

Other interpreter issues identified were non provision of interpreters and the inappropriate use of telephone interpreting:

"The issue of accessing interpreting goes in circles. It was good for a while but because of the [government financial] cuts and the drive for savings on cost effectiveness it's been pulled back again, and now there is more pressure on using telephone interpreting very inappropriately, as there is a time and place for everything," PN4

"I was with a girl [on the phone] and her friend was at the doctors and was trying to make an appointment and they won't provide an interpreter...and she is having to give the information on her behalf,"PN7

\section{Major theme 3: Risk factor exposure and mental health status in migrant communities}

in the NI context. Although not the primary focus of this study, the challenges facing migrants in $\mathrm{NI}$ and the impact on their wellbeing clearly emerged as a theme and area of 
great concern for participants in the focus groups, particularly in relation to specific differences in the $\mathrm{NI}$ context compared to other regions and countries.

Sub theme 3.1. Low paid jobs and poor working conditions. It became apparent during focus groups that migrants may be more exposed to risk factors for mental ill-health in NI. Some participants discussed how migrants were subjected to poor working conditions and low paid jobs:

"You have more Moypark [food factory] type working sometimes in 24 hour shifts and very extreme working conditions," PN2

"Also for those working in those jobs [factory work], sickness are part of disciplinary procedures, these people would rather go to work than risk this, they miss a day's work then it's a disciplinary," PN4

"Recent groups that have come in and mostly to very low wage jobs," PN3 "[The year] 2000 onwards a lot of low paid jobs that migrants are doing...we are now facing huge problem in acute poverty and debt, and add in [it has an impact on] the big issue health and well-being," PN2

Subtheme 3.2 Isolation and lack of support

It became evident that migrants' across the board may be isolated living in $\mathrm{NI}$, and a few participants identified that support structures for migrants may be an area for development:

"I think in relation to those [undocumented migrants] no one has any real support, not from the police and not from society," PN2 
"This is where I would love to see structures put in place... I mean people who are isolated in this country. Even if they look like the local indigenous population there are still issues," PN5

Sub theme 3.3. Racism/discrimination/negative behaviour towards migrants. There was a strong sense from focus group participants that racism/ discrimination and other negative behaviours towards migrants were ongoing and growing issues in $\mathrm{NI}$ :

"Add in the big issue health and well-being which takes in [is impacted by] all these issues, mental health being one of the key ones, and the increasing polarisation between the local [majority population] and those minority because of the mentality they take our house, they take our jobs,' so you have all those racist attack, hate crime, and discrimination," PN2

"Yeh [sic] there will be children playing with each other until one day the child says I can't play with you no more because my mummy said you are all bad," PN12

"My sense is that racism is increasing particularly with all the publicity at the moment about the Syrian refugees needing supported [sic] and countries to take them, there seems to be a huge polarisation of views from people who want to help to others that don't want this to happen, and some of the remarks people will make quite openly saying quite racist things,"

\section{PN3}

\section{Discussion}

This study used a qualitative methodology to explore the barriers and challenges facing migrants in responding to the Census, registering with the health service and reporting hate crimes, in order to inform population research using administrative data registers in NI. A key theme that emerged from the present study is that the use of data from registers for 
researching the number, mental health and needs of migrants in $\mathrm{NI}$ may be problematic with the potential for missing specific groups of migrants. The use of GP and Census registers for quantifying the size of the migrant population may lead to an underestimation as several issues related to migrants' ability to register with a GP and to complete the Census were identified.

The findings regarding the inability of some migrants to register with a GP in NI concurs with existing research elsewhere. HealthWatch (2015), a UK organisation set up to make sure that the local health systems listens to people's views and experiences, found that only one out of 36 practices offered an interpreter for non-English speakers when trying to register with a GP, and 19 practices advised patients to come back with a friend or family member who spoke English. The use of family members as interpreters, particularly children, is a concern as it is likely to reduce help seeking for sensitive health issues such as mental health (Kirmayer et al. 2011). The findings regarding EU migrants being refused registration at GP surgeries in NI due to not holding a passport or visa document is alarming. This suggests that there are inconsistencies and lack of knowledge in the GP registration process between GP surgeries. Therefore, to ensure consistency and improve the quality of healthbased registers, it may be beneficial for GP surgeries to receive training in the rights of EU and other migrant groups to access primary care services, particularly reception staff that frequently assist patients with registration. Research using this register in its current form must acknowledge these biases and inconsistencies in their interpretation of findings. Migrant numbers in GP records are likely to be underestimated. Consequentially, incidence of mental health disorders is likely to be affected. From the findings of this research, underestimation of mental health difficulties for undocumented migrants (such as rejected asylum seekers) and short-stay migrants (such as seasonal workers or students) are probable, whilst healthy migrants who are unfamiliar with the NI GP registration system may also be underestimated in health records. Register-based research in NI must take this into account, with particular attention to the underrepresentation of undocumented migrants who 
are likely to have worse mental health given their insecure circumstances and lack of access to support (Gray, 2012).

In addition to barriers in registering for health services, this study also highlighted many negative experiences in accessing health care services, which may also reduce the accuracy of GP records, such as the issuing of antidepressant prescriptions, with a knock on effect on research that uses this data to identify individuals suffering from mental ill health. The findings of this study highlighted sub-optimal access to interpreters and lack of cultural competence within the health care workforce. Research strongly supports that culturally competent health staff has many benefits for patients which include increased health careseeking behaviour and better adherence to medical advice (Lehman, et al. 2012). The lack of cultural awareness of health staff in NI reported by study participants suggests that health professionals may require additional training in cultural awareness. Despite an increased emphasis on cultural competence training for health professionals in recent years, the implementation of this training varies widely across programmes (George et al. 2015). This study suggests that NI has not kept up with population changes with respect to different migrant groups and their needs. Increasing the cultural competency of health staff will likely lead to improvements in migrant's experience of the health system, which will encourage help seeking, make GP records more reflective or reality and ultimately lead to improved migrant mental health.

In terms of the Census as a source of information on migrants in $\mathrm{NI}$, our study suggests there are challenges in completing the Census for these groups. Our findings in relation to language being a barrier to Census completion are supported by research conducted by the US Census Bureau (2012). Over 3\% of the NI population do not speak English as their main language and in England and Wales the percentages of residents reporting that English is not their main language is even higher at almost $8 \%$ (NISRA, 2011, ONS 2011). Without 
having adequate knowledge of the official language of the country a person is residing in, the additional steps required to obtain the Census in the appropriate language may prove difficult and may explain why those migrants not fluent with the official language of a country may not be fully represented in the Census. Similar to our findings, the research by the US Census Bureau (2012) found that migrants may not recognise the importance of completing the Census and some may perceive the Census as being only relevant for the settled majority. Findings in relation to migrants' difficulties completing the Census suggest that better support systems are needed to ensure that those with limited skills in the main language of the country are helped to complete the Census. It may also be important to ensure that migrants are better informed about the purpose of the Census and the importance of its completion. Implementing these steps may aid improved representativeness of these migrants in future Censuses and improve the quality of future linkage studies using Census registry data. This is important as the current quality of register-based linkage studies using Census will be greatly affected by the likely underrepresentation of several migrant groups. Those most likely to be unrepresented in the Census are those with limited skills in English. This is of particular importance for research on migrant mental health as those with limited host country language skills have been shown to be at additional risk of acculturation stress, which has been linked with poor psychological well-being (Liebkind et al. 2000, Yeh and Inose 2003). Therefore, underrepresentation of non-English speakers in the NI Census could mean that those at higher risk of mental ill-health may not be accounted for within the linkage study, which potentially may lead to inaccurate interpretations when comparing the risk of mental ill-health in the migrant versus the settled majority population.

Aside from GP registration and Census completion, this study aimed to explore the reporting or underreporting of hate crime in order to inform register-based research on the effect of hate crime on the mental health of migrants. Global research strongly indicates that hate crime, racism and discrimination impact negatively on migrant mental well-being (Veling et al. 2007, Bécares 2009, Bosqui et al. 2014). Therefore, it is imperative that research into migrant 
mental health take these into account when conducting migrant mental health research. In many countries residents are encouraged to report experiences of racial hate crime to police authorities, who frequently compile a register of reported racial hate crimes. This is considered important in helping police authorities keep a check on whether racial hate crime is being tackled effectively. However, concerns were raised by focus group participants regarding the use of the hate crime register data in assessing the impact of hate crime on migrant mental health, with many participants drawing attention to the fact that hate crime is often underreported. This is supported by research in England and Wales which suggests that only $40 \%$ of hate crime is brought to the attention of police and just $20 \%$ is officially recorded (College of Policing, 2014). Our findings in relation to the reasons for underreporting of racial hate crime also concur with previous research conducted in $\mathrm{NI}$ and in the EU (European Agency for Fundamental Rights 2012; NICEM 2014). Commonly cited reasons for not reporting a racial hate crime to police were due to failure of a previous report of hate crime/racism leading to prosecution, or specific to the NI context, due to legacy issues related to civil conflict known as "The Troubles." This was thought to lead higher tolerance to abuse. Tackling racial hate crime and increasing the reporting of racial hate crime are seen as important priorities in many EU counties and steps are continually being taken to eradicate racial hate crime and to make countries more cohesive. However, despite concentrated efforts in recent years in NI to encourage the reporting of racial hate crime e.g.: hate crime telephone line, the present findings strongly suggest that more work is needed. For register-based research using hate crime data, researchers must acknowledge the limitations of these data and that recorded hate crimes are likely to underestimate the reality of hate crimes, racism, prejudice, hostility and discrimination faced by migrants in NI every day.

The final theme which emerged from this study indicated that the mental health of migrants and their exposure to risk factors was of particular concern to our participants, and highlights 
the importance and need for good quality robust research on the mental health of migrants in NI. Migrants were identified as being more likely to be exposed to risk factors which increased their risk of mental ill-health including low paid jobs and poor working conditions, isolation, lack of social support and experiences of racism. The poor working conditions that many migrants in $\mathrm{NI}$ experience was highlighted by several participants who reported on circumstances where migrants worked long hours for low wages and were also unable to take off work to visit the doctor for fear of disciplinary action. These experiences could have a serious impact on migrant mental health. Poor working conditions of migrants in the UK have been shown to be associated with depressed mood and hopelessness (Wu et al. 2010). Low paid jobs that many migrants enter into when they arrive in NI may mean they are more likely to be living in poverty and more likely to experience debt, all of which are associated with mental ill health (Jenkins et al., 2008). The findings regarding migrants being isolated and lacking social support is also concerning, as are the findings on racism being an ever present and growing issue. These findings suggest that the current systems in place to make NI a more cohesive society after the Good Friday Peace Agreement in 1998 are failing and further efforts may be needed to improve migrant integration with the settled NI population. The need for robust research on the mental health of migrants in this context is clear.

To conclude, findings from this study suggest that research drawing on data from routine registers such as Census and GP registration to research migrants and their respective mental health needs may underestimate the size of the migrant population, the incidence of mental disorders compared to the settled majority, and migrants' need for mental health services. Our findings suggest those migrants which appear most likely to be unrepresented in these registers are non-English speaking migrants, recently arrived migrants with limited knowledge of the health system and undocumented migrants. The under-representation of these particular groups of migrants is concerning as these migrants are likely to be the most adversely affected by traumatic migration routes and acculturation stress. It is therefore important that the possible underrepresentation of the mental health needs of these 
populations is considered carefully when interpreting the findings of register-based studies in NI. Finally, the findings from the study also identified a need for further research on migrant mental health, highlighting higher exposure to risk factors for mental ill-health.

\section{Limitations}

The primary limitation of this study is the fact that the findings are only directly applicable to the NI population. However, they may prove helpful for guiding researchers proposing similar linkage studies in other countries. Furthermore the study is limited by the fact that the focus groups did not continue to the point of data saturation, and focused only on professional's views. Due to time and resource constraints it was not possible to organise groups with migrant groups themselves, with a particular need to speak to undocumented, short-term and non-English speaking migrants. Future register-based research would benefit from these insights.

\section{References}

Bécares, L., Nazroo, J. and Stafford, M. (2009), "The buffering effects of ethnic density on experienced racism and health", Health Place, Vol. 15, pp. 700-708.

Borque, F., Van der Ven, E. and Malla, A. (2011), "A meta-analysis of the risk for psychotic disorders among first and second generation immigrants", Psychological Medicine , Vol. 41, No.5, pp. 897-910.

Bosqui, T.J., Hoy, K. and Shannon, C. (2014), "A systematic review and meta-analysis of the ethnic density effect in psychotic disorders", Social Psychiatry and Psychiatry Epidemiology, Vol. 4, pp 519-29.

Bronstein, I., and Montgomery, P. (2011), "Psychological distress in refugee children: A systematic review", Clinical Child and Family Psychology Revie , vol 14, no.1, pp. 4456. 
College of Policing. (2014), "Hate crime operational guidance", available at:

http://www.college.police.uk/What-we-do/Support/Equality/Documents/Hate-CrimeOperational-Guidance.pdf (accessed 24 May 2016)

Dustman, C. and Frattinni T. (2011), “Immigration the European experience”. Centre for Research and analysis of migration at University College London, available http://www.ucl.ac.uk/ uctpb21/doc/CDP 22 11.pdf (Accessed 9 June 2016)

European Agency for Fundamental Rights. (2012), "Making hate crime visible in the European Union: acknowledging victims' rights", available at: http://www.reportit.org.uk/files/fra-2012 hate-crime[1].pdf (Accessed 20 May 2016)

Franks, W., Gawn, N. and Gillian, B. (2007), "Barriers to access to mental health services for migrant workers, refugees and asylum seekers", Journal of Public Mental Health, Vol. 6, No. 1 , pp. $33-41$.

Gray, B.H. and Van Ginneken, E. (2012), "Health care for undocumented migrants: European approaches", Commonwealth Fund, Vol 33, pp. 1-12.

George, E., Thornicroft, G. and Nisha, D. (2015), "Exploration of cultural competency training in UK healthcare settings: A critical interpretive review of the literature", Diversity \& Equality in Health \& Care, Vol. 12, No. 3, 104-115.

HealthWatch Islington. (2015), "Registering with a GP is hard if you don't speak English", available at: http://www.healthwatchislington.co.uk/sites/default/files/winter_2015_newsletter_eversion.pdf (accessed 4 December 2015)

Hollander, A.C (2013), "Social inequalities in mental health and mortality among refugees and other immigrants to Sweden--epidemiological studies of register data", Global Health Action, Vol. 6, pp. 210-259. 
Jayaweera, H. and Quigley, P. (2010), "Health Status, Health Behaviour and Healthcare Use among Migrants in the UK: Evidence from Mothers in the Millennium Cohort Study", Social Science \& Medicine, Vol. 71, pp. 1002-1010.

Jenkins, R., Bhugra, D., Bebbington, P. and Brugha, T. (2008). Debt, income and mental disorder in the general population. Psychological Medicine, Vol. 38, No.10, 14851493.

Keynejad, R. (2008), "Barriers to help seeking: What stops ethnic minority groups in Redbridge accessing mental health services?", available http://www.rcmh.org.uk/documents/reports/barrierstoseekinghelp.pdf (accessed 16 October 2015)

Kirmayer, L., Narasiah, L., Munoz, M., Rashid, M., Ryder, A. G., Guzder, J., Hassan, G., Rousseau, C. and Pottie, K. (2011), "Common mental health problems in immigrants and refugees: general approach in primary care", Canadian Medical Association Journal, Vol 183, No.12, doi: 10.1503/cmaj.090292

Krausova, A., and Vargos Silva, S. C. (2014), "Briefing The Northern Ireland Census Profile, The Migrant Observatory at the University of Oxford", available at: http://www.migrationobservatory.ox.ac.uk/sites/files/migobs/Briefing\%20\%20Northern\%20Ireland\%20census\%20profile 0.pdf (accessed 20 May 2016)

Lehman, D., Fenza, P. and Hollinger-Smith, L. (2012), "Diversity \& Cultural Competency in Health Care Settings", available at; http://www.matherlifewaysinstituteonaging.com/wp-content/uploads/2012/03/diversityand-cultural-competency-in-health-care-settings.pdf (accessed 16 April 2016)

Liebkind, K., and Jasinkaja-Lahti, I .(2000), "Acculturation and Psychological Well-Being among Immigrant Adolescents in Finland.A Comparative Study of Adolescents From Different Cultural Backgrounds", Journal of Adolescent Research, Vol 15, No. 4, pp. 446-469. 
Lindert, J., Ehrenstein, O.S., Priebe, S., Mielck, A. and Brahler, E. (2009), “Depression and anxiety in labor migrants and refugees-A systematic review and meta-analysis", Social Science and Medicine, Vol.69, pp.246-257.

Matsumoto, D. (2001), The handbook of culture and psychology, Oxford University Press, New York.

Northern Ireland Council for Ethnic Minorities NICEM. (2014a). "Voices for change: Mapping the views of black and minority ethnic people on integration and their sense of belonging in Northern Ireland", available at: http://nicem.org.uk/wpcontent/uploads/2015/01/VOICES-FOR-CHANGE-NICEM-2014.pdf (accessed 23 May 2016)

Northern Ireland Council for Ethnic Minorities NICEM. (2014b,) "NICEM briefing paper consultation document", available at: http://nicem.org.uk/wpcontent/uploads/2014/08/NICEM-RES-Briefing-Paper-July-2014.pdf (Accessed 1 May 2015)

Northern Ireland Research and Statistics Agency NISRA. (2012), “Census 2011: Key statistics for Northern Ireland", http://www.nisra.gov.uk/Census/key report 2011.pdf (accessed 23 March 2016)

Norredam, M., Agyemang, C., Hoejbjerg Hansen, O.K., Petersen, J. H., Byberg, S., Krasnik A. and Kunst, A. E. (2014), "Duration of residence and disease occurrence among refugees and family reunited immigrants: test of the 'healthy migrant effect' hypothesis", Tropical Medicine \& International Health, Vol. 19, pp. 958-967.

Ozbay, F., Johnson, D.C., Dimoulas, E., Morgan, C.A., Charney, D.and Southwick, S. (2007), "Social Support and Resilience to Stress: From Neurobiology to Clinical Practice", Psychiatry (Edgmont), Vol. 4, No.5, 35-40. 
Patel, K., Kouvonen, A., Close, C., Väänänen, A., O’Reilly, D. and Donnelly, M. (2017), What do register-based studies tell us about migrant mental health? A scoping review. Systematic Reviews, Vol 6, 78.

Phillimore, J. (2011), Approaches to health provision in the age of super-diversity: Accessing the NHS in Britain's most diverse city. Critical Social Policy, Vol. 31, No.1.

Police Service of Northern Ireland. (2014), "Incidents and Crimes with a Hate Motivation Recorded by the Police in Northern Ireland", available at:

https://www.psni.police.uk/globalassets/inside-the-psni/our-statistics/hate-motivationstatistics/archive/quarterly hate motivations bulletin apr-mar 13 14.pdf (accessed 20 May 2016)

Russell, R (2012), "Northern Ireland Assembly Research and Information Service paper. Migration in Northern Ireland. Available at : http://www.niassembly.gov.uk/globalassets/documents/raise/publications/2012/gener al/3112.pdf (accessed 22 April 2016)

The Migration Observatory. (2014), "Changes in the international migration population of Northern Ireland 2001-2011", available at: http://www.migrationobservatory.ox.ac.uk/press-releases/changes-internationalmigrant-population-northern-ireland-2001-2011 (accessed 22 April 2016)

Tong, A., P Sainsbury , J. Craig (2007), "Consolidated criteria for reporting qualitative research (COREQ): a 32-item checklist for interviews and focus groups", International Journal for Quality in Health Care, Vol. 19, No. 6, 349 - 357.

US Census Bureau. (2012). Observing Census Enumeration of Non-English Speaking Households in the 2010 Census: Evaluation Report, available at: http://www.census.gov/2010census/pdf/2010_Census_Enumeration_NonEnglish_Speaking_Households.pdf (accessed 23 May 2016). 
Sandelowski, M. (2000), "Focus on Research Methods: What ever happened to Qualitative Description?", Research in Nursing \& Health, Vol. 23, pp.334-340.

Veling, W., Selten, J.P., Susser, E., Laan, W., Mackenbach, J. P. and Hoek, H.W. (2007), "Discrimination and the incidence of psychotic disorders among ethnic minorities in The Netherlands", International Journal of Epidemiology, Vol 36, No. 4, pp.761-8.

Wu, B., Sheehan, J. and Guo, L. (2010), “Economic Recession, Employment and working conditions of Chinese migrant workers in the UK", available at: The University of Nottingham, China Policy Institute.

https://www.nottingham.ac.uk/cpi/documents/briefings/briefing-62-ilo-migrantworkers.pdf (accessed 23 May 2016)

Yeh, C. J., Inose, M. ( 2003), “International students' reported English fluency, social support satisfaction, and social connectedness as predictors of acculturative stress". Counselling Psychology Quarterly, Vol. 16, No. 1, 15-28. 


\section{Appendix 1: Topic schedule}

1. Tell me about the diversity of migration experiences in Northern Ireland which you are aware off

2. Tell me about your knowledge of the scale of undocumented or irregular migration to Northern Ireland

3. Describe to me what you know about migrant's general knowledge, experience and perceptions of the Census- prompt- Are there any groups of migrants that may not be complete the Census?

4. Describe to me what you know about migrant's general knowledge, experience and perceptions of registering with a GP practice- Prompt- Tell me about any groups of migrants that may not be registered with a GP?

4. Tell me about migrants' experiences of the health and social care system-Prompt-Tell me any areas of the Health and Social Care system that may require improvement in order to enhance migrants' experiences of Health and Social Care?

5. Tell me what you know about the scale of unreported experience and exposure to racism and discrimination- Prompt-Tell me your views on whether incidences of racism and discrimination are increasing or decreasing?

6. Tell me what you know about migrant's experience and perceptions of reporting racism and racist hate crimes-Prompt-Tell me about your views on whether racial hate crime is being reported accurately? 
Table 1: Migrant focus group demographics

\begin{tabular}{|l|l|l|l|}
\hline & Focus group 1 $(\mathrm{n}=10)$ & Focus Group 2 $(\mathrm{n}=7)$ & Overall \\
\hline Mean age (years) & 46.8 & 50.5 & 48.3 (range 19-66) \\
\hline Gender & 1 male and 9 females & 1 male and 6 & 15 females and 2 \\
& & females & males \\
\hline BKorn outside & Yes=4No=6 & Yes=2 No=5 & Yes=6,No=11 \\
\hline
\end{tabular}


Table 2: Details on focus group participants job roles

\begin{tabular}{|c|c|c|}
\hline Participant number (PN) & Job role & Length of time in this role \\
\hline 1 & $\begin{array}{l}\text { Community Development } \\
\text { Worker }\end{array}$ & 12 years \\
\hline 2 & $\begin{array}{l}\text { Manager of a Migrant and Ethnic } \\
\text { Minority Support organisation }\end{array}$ & 10 years \\
\hline 3 & Health Improvement Worker & 10 years \\
\hline 4 & Community Interpreter & 12 years \\
\hline 5 & $\begin{array}{l}\text { Migrant/ ethnic minority support } \\
\text { worker }\end{array}$ & 7 years \\
\hline 6 & $\begin{array}{l}\text { Volunteer migrant/ Ethnic } \\
\text { minority support worker }\end{array}$ & 2 years \\
\hline 7 & $\begin{array}{l}\text { Migrant/ ethnic minority Support } \\
\text { Worker }\end{array}$ & 5 years \\
\hline 8 & $\begin{array}{l}\text { Volunteer migrant/ ethnic } \\
\text { minority support worker }\end{array}$ & 1 year \\
\hline 9 & $\begin{array}{l}\text { Health Improvement Worker/ } \\
\text { Complementary therapist }\end{array}$ & 6 years \\
\hline 10 & $\begin{array}{l}\text { Migrant/ ethnic minority Support } \\
\text { Worker }\end{array}$ & 0.5 years \\
\hline 11 & $\begin{array}{l}\text { Manager of a Migrant and Ethnic } \\
\text { Minority Support organisation }\end{array}$ & 4 years \\
\hline 12 & $\begin{array}{l}\text { Manager of a Migrant and Ethnic } \\
\text { Minority Support organisation }\end{array}$ & 5 years \\
\hline 13 & $\begin{array}{l}\text { Manager of a Migrant and Ethnic } \\
\text { Minority Support organisation }\end{array}$ & 6 years \\
\hline
\end{tabular}




\begin{tabular}{|l|l|l|}
\hline 14 & Manager of a Migrant and Ethnic & 5 years \\
& Minority Support organisation & \\
& Community Development & 2 years \\
& Minorities & \\
\hline 16 & Health Improvement Worker & 1 year \\
\hline 17 & Health improvement Worker & 3 years \\
\hline
\end{tabular}


Table 3: Themes and sub-themes identified through framework analysis of transcription

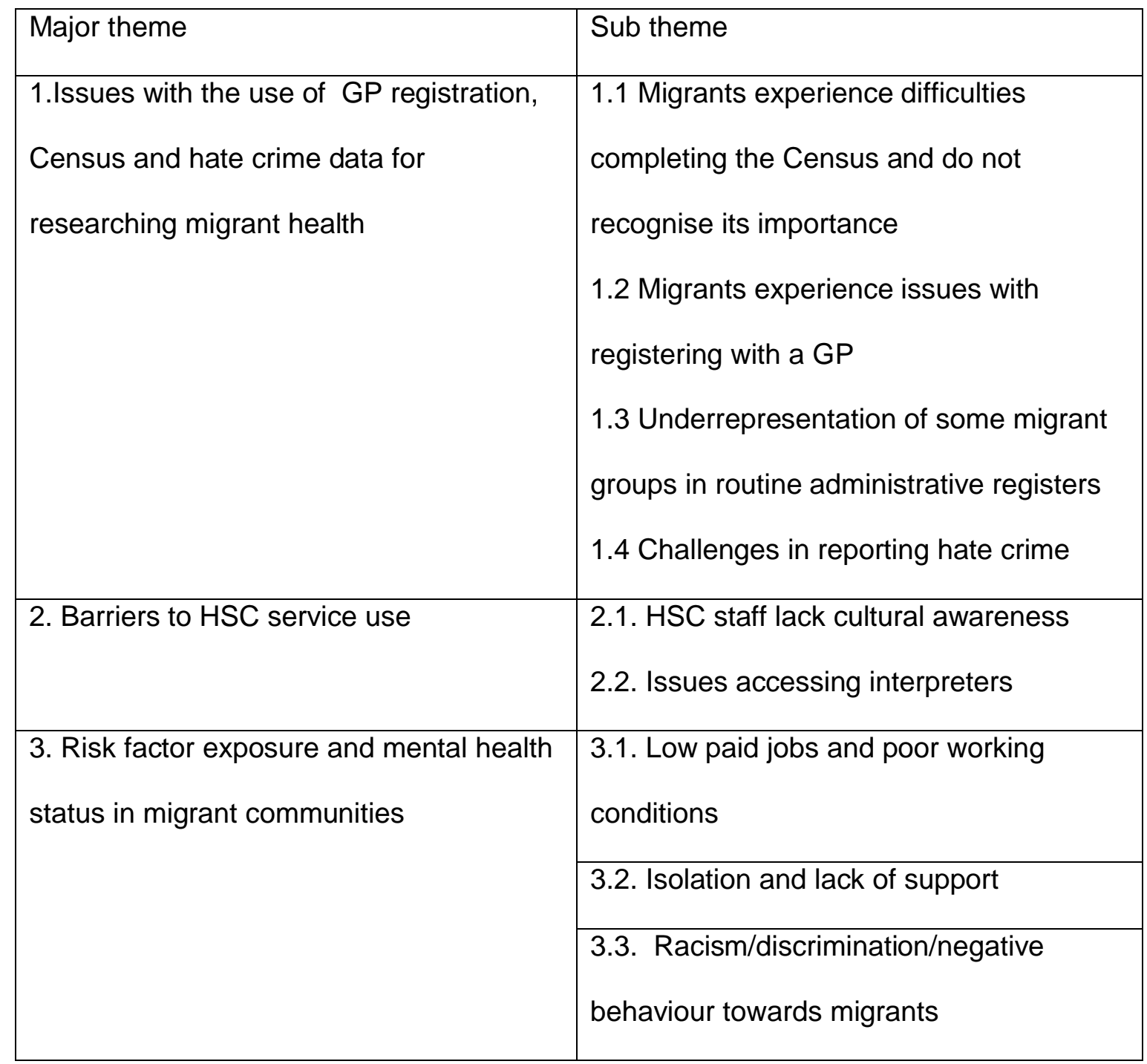

